\title{
Crossing Borders: Social Sciences and Humanities Perspectives on European Energy Systems Integration
}

\author{
Antti Silvast, Ronan Bolton, Vincent Lagendijk, \\ and Kacper Szulecki
}

Abstract Our chapter brings together four Social Sciences and Humanities (SSH) scholars into a conversation about their research and policy engagements, working within History, Political Science, Sociology, and Science and Technology Studies. We develop a socio-technical perspective and turn that into a conceptual tool pack, to interrogate and explore the

\footnotetext{
A. Silvast $(\bowtie)$

Department of Anthropology, Durham University, Durham, UK e-mail: antti.e.silvast@durham.ac.uk

R. Bolton

School of Social and Political Science, University of Edinburgh, Edinburgh, UK e-mail: Ronan.Bolton@ed.ac.uk

V. Lagendijk

Department of History, Maastricht University, Maastricht, Netherlands e-mail: vincent.lagendijk@maastrichtuniversity.nl

K. Szulecki

Department of Political Science, University of Oslo, Oslo, Norway e-mail: kacper.szulecki@stv.uio.no

(C) The Author(s) 2018

C. Foulds, R. Robison (eds.), Advancing Energy Policy, https://doi.org/10.1007/978-3-319-99097-2_7
} 
emerging concept of Energy Systems Integration (ESI) with a special interest in European energy integration. Our contributions include, first, advancing the concepts of socio-technical energy system and seamless web for our research topics. Second, we open up select frameworks for ESI using the socio-technical perspective and highlight very different interpretations of systems integration terminologies and their effects. Third, the chapter explores of how the production of scale matters greatly for integrated energy systems, from a variety of infrastructural scales to urban, national, and supranational scales. The chapter rounds up by suggesting ideas for future interdisciplinary research between SSH researchers and designers of more integrated energy systems.

Keywords Large technical systems $\bullet$ Infrastructures $\bullet$ Science and Technology Studies • Political Science • History

\subsection{INTRODUCTION}

What can academic disciplines from the Social Sciences and Humanities (SSH) offer to understand how Europe will reach its targets of affordable, reliable, and sustainable energy? Our chapter focuses on a variety of energyrelated SSH research, and unpacks its implications for energy policy by bringing together four SSH scholars into a conversation about their research and policy engagements. We work within History, Political Science, Sociology, and Science and Technology Studies, and our projects have been funded by different councils and public as well as private donors in different national and international contexts: the EU Horizon 2020 and research councils and foundations in various countries (UK, Norway, Poland, and the Netherlands).

The key object of this chapter concerns the concept of Energy Systems Integration (ESI) with a special interest in European energy integration. This concept has been emerging in expert circles through specialised associations, conferences, and research projects for a number of years. The International Institute for Energy Systems Integration was founded in 2014 to address cross-sectoral integration of multiple energy systems, and mainly its technical challenges. It defines the concept as the following activity: 'Energy Systems Integration (ESI) is the process of coordinating the operation and planning of energy systems across multiple pathways and/or geographical scales to deliver reliable, cost effective energy services with minimal impact on the environment' (O'Malley et al. 2016, p. 1).

Systems integration visions also feature prominently in the European Commission's (2017) Strategic Energy Technology (SET) Plans-where 
the greater integration between heating, cooling, energy storage, energy efficiency, demand-side responses, and renewable energies appears as the next advancement in the context of 'smart' projects such as 'smart grids' or 'smart cities'. Similar visions have underpinned the EU's Energy Union (European Commission 2015), a strategy for European energy policy integration across cutting carbon to energy security, internal markets, innovation, and energy efficiency. The concept of ESI is also central to large research programmes including research universities and companies. One recent example is the collaboration of five UK universities and Siemens in the Centre for Energy Systems Intergration (CESI).

While ESI emerged mainly from technological fields, it involves significant SSH-related issues. In this chapter, we develop a socio-technical perspective to interrogate and explore a set of these issues. We are speaking primarily from our interest in Science and Technology Studies, while our varied disciplinary backgrounds represent a good sample of SSH. We argue that this subset offers well-developed concepts and tools for framing today's energy problems, and thus helps to formulate more thorough and robust solutions. This critical edge has policy relevance of its own. But in place of problem-solving blueprints, it helps to adjust the premises on which energy debates are set, the conceptual tool pack which we use to propose and design policies, and the perspectives for evaluating the pros and cons of different technical and political-administrative solutions.

Our chapter speaks to several themes from this edited book. The contributions include, first, addressing what SSH scholars understand by the concepts of socio-technical energy systems and their technopolitics (Hecht 2011 ) in matters of integration. These terms refer to an energy system that cuts across technological, political, social, disciplinary, jurisdictional, and organisational boundaries. This system forms what researchers name a seamless web (Hughes 1986), requiring strong collaboration between different academic disciplines and their knowledge practices in order to fully appreciate its technical and societal embeddedness (Winskel 2018). Second, we open up select frameworks for ESI using the socio-technical systems perspective and highlight the clear interpretative flexibility (Pinch and Bijker 1984) of various systems integration terminologies and their effects in so doing. Third, the chapter explores how the production of scale matters greatly for integrated energy systems in various meanings of the term-different infrastructural scales (Edwards 2003), the urban scale (Bolton and Foxon 2013), the national scale, and the supranational scale (Van der Vleuten 2004; Lagendijk 2008). The chapter rounds up by suggesting ideas for future interdisciplinary research and interactions between 
SSH researchers and designers of more integrated energy systems. Each of these contributions is discussed in its own subsection in order.

The chapter was built upon an internal researcher workshop held at Durham University on 28 March 2018, between the four authors. Written up, this piece allows our readers to listen in on our conversations on our respective positions on Energy Systems Integration and engagement with academic SSH perspectives. Box 7.1 contains a more detailed explanation of the interdisciplinary workshop methodology for this chapter.

\section{Box 7.1 Interdisciplinary workshop methodology for the development of research outputs}

1. All involved scholars identify relevant calls for workshop funding and develop an agenda to answer these concerns.

2. The workshop coordinator finds and contacts more scholars on the basis of the initial agenda.

3. The coordinator, together with other participants, develops a small number of orienting questions to the workshop discussion, building upon the initial agenda.

4. All scholars circulate a short abstract that addresses the questions, done at least one week before the workshop.

5. During the workshop, participants discuss the questions in order but also allow the discussion to move to new topics. The workshop starts with an introductory comment by each scholar and then allows all scholars to comment and discuss freely. The discussants are encouraged to present concrete problems and operational research concepts in order to avoid disciplinary biases shaping the discussion. Each participant takes notes, but the workshop is also recorded to ensure their accuracy.

6. After the discussion, the participants continue the workshop by jointly typing up key themes that emerged from the workshop.

7. After the workshop, the coordinator uses these notes to draft the first version of the paper.

8. Each participant comments on the draft before the submission.

9. The submission is subjected to peer review in the normal academic fashion.

10. Based on peer-review comments, the coordinator drafts the final output acknowledging comments from the other authors. 


\subsection{Integrated Socio-Technical Systems and the Seamless Web Approach}

Appreciating energy integration requires, at once, historical awareness of earlier integrated systems and the ways in which such integration has crossed boundaries from technical to different social arenas. With this issue in view, all SSH scholars involved in the workshop likened the electricity system to what historian Hughes (1986) has called a seamless weban underlying idea shared in many wider Science and Technology Studies literatures (Bijker et al. 1987). At the core, the seamless web approach goes against professional or jurisdictional boundaries, disciplines, or categories of knowledge. Hughes argued that the integrating visions of inventors, managers, and engineers of technological systems always themselves crossed these dichotomies such as 'technology and science, pure and applied, internal and external, and technical and social' (Hughes 1986, p. 286). Furthermore, his research strongly emphasised that the system's components are commonly controlled and interact to fulfil a system goal. These goals can change over time-as can secondary policy goals and interpretations of energy issues-from security of supply to providing energy at the lowest possible price, or attaining sustainability aims.

What does this imply for how we should see energy systems? To us, it makes no sense to see the system as something purely technical and disconnected from other social and economic issues. Technological solutions only do not solve contemporary energy issues - think about local protests over energy grid extensions and wind farms or privacy risks some have associated with new energy smart metres. To focus on technologies only is to ignore the social embeddedness of technical artefacts and systems. Like Hughes (1986, p. 290) argued, we see the social and political embodied into the technical realm-something Gabrielle Hecht (2011) has labelled technopolitics. This means that a change in a system's goal will affect the components, and changes to components have consequences for the system's functioning.

When seeing them as seamless and socio-technical, systems immediately become interdisciplinary objects of study. Understanding historical shaping and current-day constellations of energy infrastructures requires technological, scientific, economic, sociological, anthropological, and political scientific lenses to fully grasp these systems. These concepts are very consequential for framing how we approach Energy Systems Integration. If we assume that integrators of energy systems are bounded 
by their disciplines, there is little need for more interdisciplinary research. But if we presume that the integrators of energy systems are problemsolvers to whom categories such as disciplines are soft and overlapping, then our analysis needs to be attuned to how that happens in practice, not simply assuming boundaries such as professions, disciplines, or nationstate borders. A socio-technical system like the grid combines the materiality of its physical infrastructures and the institutions and norms which emerge to govern it, as well as the broad set of practices that keep these together and enable the very functioning and use of the system. It is in the study of the establishment and change of these practices (and the related practical logic) that our contribution is anchored.

Hughes's (1986) historical work makes another important contribution in that visions for integrated systems, so common today, are not new. They go back to the invention of earliest electric power networks and other similar large-scale systems (Van der Vleuten 2004). Another important facet has been the social integration of engineers and inventors that aspired to build large energy systems. In Europe, the relevant engineering networks that envisioned a common electricity grid date to the early twentieth century (Lagendijk 2008). Hence, the ideal of supranational integration of energy systems predates the European Union (EU) by several decades. Energy integration does not simply equate to European integration along the lines of the EU.

As technology histories have shown, these earlier eras' energy systems builders were relatively easy to identify, being privileged actors (Van der Vleuten 2004) and varying from individual inventors, managers and engineers to investors and, especially with cross-border systems, international organisations of engineers. Concerning ESI, the relevant systems building is still emerging, and the actual systems integrators remain sometimes only implicit in discussions of the concept.

With regard to these systems builders, we seek to highlight three points. Firstly, at the moment, the concept of ESI seems to be emerging among policymakers and industrialists that might see themselves as systems integrators. Secondly, international and national networks and research projects that pursue Energy Systems Integration are very important for the social shaping of ESI. As such, they are often formed by academic researchers, especially modellers, analysts, and designers in engineering and scientific disciplines. But these communities can also include more policy-facing researchers and social scientists-especially when the integration of different disciplines (social, physical, and environmental) and interdisciplinary 
whole systems research are concerned (Winskel 2018). Thirdly, the commercial and economic principles of ESI remain underexplored but point to the importance of firms and energy market regulators as both shapers and potential beneficiaries of ESI (e.g. Farsi et al. 2008).

By bringing socio-technical infrastructures and these different designers and builders into a sharper focus, our perspective in this chapter joins and complements a particular approach of many of the texts in this edited book (Higginson et al. 2018, Chap. 5 in this collection; Genus et al. 2018, Chap. 9; Middlemiss et al. 2018, Chap. 2) and recent SSH discussions. This approach is the study of the meanings, competences, and materialities (e.g. household technologies and objects) underpinning social practices such as everyday energy use (Shove et al. 2012). The seamless web concept is also deeply interested in the everyday lives and practices of energy consumers but in a specific way. Its point is not to separate social practices and the energy system 'out there' but to view everyday life in the way in which problem-solvers of systems integration might see it. This means closely considering how the practices of energy users are anticipated and included in the design of more integrated system, whether it be in their technical specifications, inputs to whole energy systems models, or associated political values, standards, or legislations. Everyday life has a clear dynamic of its own that needs to be studied in its own ways and contexts; its integration and interaction with other energy system 'components' of various kinds are what concerns the seamless web approach in particular.

\subsection{Frameworks For Energy Systems InTEgration}

Like other contemporary energy terms - such as 'smart grids' - there is no single universal definition for Energy Systems Integration. Having said that, experts constantly associate specific values and valuations to more integrated energy systems, which are highly suitable for SSH interrogation as we show here. ESI, in its different guises, implies going beyond the limits of established organisational, jurisdictional, technological, and knowledge boundaries, which have framed centralised energy systems in Europe and other industrialised countries. This will be problematic for some actors, who may resist such changes; but it may also provide opportunities for other actors to reshape boundaries and create and capture the new sources of economic value which, according to the outputs of whole systems modelling, will arise from this integration. 
In general, ESI is an emerging policy concept, with raising industrial interest, and with research being built around it as we speak. But it is also important to highlight that the concept has demonstrable interpretative flexibility (Pinch and Bijker 1984): different research initiatives may think of and interpret ESI differently, even offering very different designs for building these systems. It is not yet clear whether a coherent view on ESI will emerge or whether it will be constituted by many local and potentially incompatible interpretations. These interpretations can be imbued by very different social and political values: as SSH scholars know, energy technology is often designed in a way that enacts certain political goals. For example, in the European context, the values have ranged from grand visions of energy integration to pragmatic considerations of its technical and economic impacts and benefits (Bolton et al. 2018).

With these values and goals in view, the idea of ESI embeds the idea of a very inclusive energy system connecting everything. It also embeds the idea that incumbent infrastructures such as large gas and electricity distribution grids do not become redundant in the face of energy innovation. Rather, they can latch onto innovative energy technologies such as smallscale renewables and advances in 'smart grids' and other transitions that the systems are facing. Indeed, influential definitions very closely associate the value of ESI in minimising environmental impact (O'Malley et al. 2016) and hence energy transition. In so doing, systems that have already grown and become consolidated can find a new pathway by being more integrated with other emerging more sustainable energy systems. Finally, ESI seems to embody certain preference for system authorities and controllers-actors not as prominent for decades with the aspiration of liberalising infrastructure industries. More than market-based management, energy integration is an active process that actors partake in. Their role is coordinating this process including real-time operation and long-term planning. A major role will be played by analysers and designers of integrated systems that are meant to influence industries and policymakers, who we term systems integrators in this piece.

Very different system goals can be fulfilled by this ESI drawing upon various principles. One apparent goal follows an engineering logic. Here, ESI is done to optimise the inputs and outputs of infrastructure, where the isolation of energy carriers has led to resource inefficiencies, and better preplanning of these synergies would help realise the current energy transition. Another is a market policy logic. This logic is not directly about infrastructure but about how to organise the power market on a large scale 
so that it has energy resources and a large number of participants to enable competition and lowering prices. Both logics constitute a challenge to the national energy sovereignty logic, which drives many policy decisions in the EU and nationally (Szulecki and Westphal 2014; Szulecki and Kusznir 2018).

These logics are obviously different, but they can also overlap especially in the aspiration to optimise future energy systems. The term technoeconomic modelling captures models of integrated systems that optimise energy systems for minimum costs and maximum welfare. One frequently used example of this is the TIMES model, which, as the Scottish Government (2016, p. 1) points out, is both 'a technical engineering approach and an economic approach'. This dual approach feeds into asking how much will the energy transition, for example, integrating an increasing amount of renewable energies in the power grid, cost to our society.

\subsection{Scales of Energy Systems Integration}

The values and logics of ESI are opened further by paying close attention to the variety of scales that they produce. All infrastructures embody multiple scales-power infrastructure, for example, exists at each household but also in utilities and transnational markets (Edwards 2003) -and one question for analysis becomes at which scale are we exploring the infrastructural system (Goldthau 2014). Another related concern, as scholars highlight in this edited collection, is that scales are not just fixed like administrative categories but produced by the very work of scaling via social processes, power, and contestation (Bridge et al. 2018, Chap. 11 in this collection).

With respect to ESI, there are many ways to do such scaling work. Integration of energy systems can happen across national borders, as well as across regions. The problematic of EU energy islands that lack international electricity or gas interconnectors to the EU's single energy system is one example of this scaling-where scale draws boundaries around regions and represents them as isolated from other scales. There is also integration across energy carriers - for example, hydrogen with gas-whether on a regional or supranational level such as the North Sea countries. Furthermore, energy integration can happen across urban infrastructures, on specific areas like a city, concerning how electrification comes together with heating or public transportation, for example. These scales are not 
fixed but change as the systems change; certain scales can be prioritised over others, depending on who controls the integration process.

On the other hand, at least as far as the EU and the power sector are concerned, a key reason for an apparent failure to achieve full ESI has been that processes of techno-economic and political integration have been happening at different speeds and, to some extent, at different scales, creating a disconnect. The former involves the building of the internal electricity market, with its infrastructural and procedural elements such as transmission lines, international interconnectors, market-coupling schemes, modelling of physical electricity flows, transfer of statistics, and common network codes. The elements of these processes are gradually put into place in the EU. The latter involves EU-level energy policy integration, which accelerated about a decade ago with the Third Energy Package (European Parliament and Council 2009) and led all the way to the Winter Package (European Commission 2016) following the Energy Union framework (European Commission 2015) - see, for example, Szulecki and others (2016). While obviously very closely related, it is testimony to the relevant problem-solving practices how often these two realities of integration stay apart. The recent Norwegian political debates and protests against ACER—the EU's official energy regulatory agency-offer an uncommon glimpse into a situation where techno-economic integration is actually associated with critical questions on centralised decision-making, power, and national sovereignty.

This leads to the final elephant in the room that needs to be addressed, especially when we speak of European Energy Systems Integration, the national scale. The centralised systems we have today were the result of choices made about scales, both explicit in political decisions and in business models and implicit in regulatory frameworks, industry codes, and engineering practices. From a techno-economic point of view, energy systems have very rarely respected national borders. The notion of national energy systems emerged only in the early 1910s, when many important cross-border micro-regional systems where already in place-and on the initiative of nationalistically minded governments (Schot and Lagendijk 2008). The engineers and managers of energy systems have sought for increased efficiency by integrating power resources across national borders, via synchronised power grids like Central Europe (Lagendijk 2008) and single power markets like the Scandinavian Nord Pool (Silvast 2017). From a more political point of view, however, states have almost always been tremendously important in matters of energy security of supply-that is, 
'keeping the lights on'-and the exploitation of energy resources. The power sector was perhaps the last to be 'overtaken' by national governments, once borders between systems were drawn and utility monopolies emerged as the most popular business model for national energy provision (Bakke 2016).

The EU's Lisbon Treaty (Treaty of the Functioning of the European Union 2012) Article 194, which formally defined EU energy policy for the first time, even directly reflects this by making energy a shared competence between the EU institutions and the members (Szulecki and Westphal 2014). This principle means that the EU will act on energy policy in the areas of single markets, sustainability, and European security of supply. But other areas such as the use of national energy resources are decisions by the member states and can be fully legislated by them.

To sum up, we need to open up a discussion about the political dimensions of energy system scales. We need to interrogate at which scale(s) Energy Systems Integration is taking place and the implications of this. In so doing, SSH researchers need to be careful not to presume that the nation state will be the leading actor in matters of integration and to be alert as to how ESI might challenge the dominance of the national scale and create new cross-scale linkages.

\subsection{Conclusion: Towards a Social Study of Energy Systems INTEGRATION}

If ESI is to unfold as a research concept and a policy idea, there needs to be space made for a well-developed socio-technical perspective on its logics and practices. This implies reaching a number of related research goals. For one part, the socio-technical aspect of ESI is closely linked with developing a better understanding of energy consumption practices in integrated energy systems. The public reservations to infrastructure expansion, something which ESI often implies, offer an apparent example of how these issues can bite back if they are not sufficiently attended. SSH researchers can bring the 'seamless web' about by diagnosing and understanding these kinds of reservations. A considerable amount of work done under the banners of 'energy justice', 'energy democracy', and political participation (e.g. Jenkins et al. 2016; Szulecki 2018) has already made policymakers and engineers more aware that they themselves and energy technologies do not function in a socio-political vacuum. 
At the same time, many benefits of ESI may actually not be achieved because of a mismatch between broader techno-economic dynamics and political and social processes. This situation calls for other tools and approaches by SSH researchers: a socio-technical perspective, which is more embedded within and engaged with the technical aspects of ESI research and practice. Rather than bracketing them out, this research should look at and problematise the socio-technical aspects of integrative energy systems and their interfaces to society, taking both historical continuities and discontinuities into account when studying these issues. Technical analysts themselves have provided detailed and useful definitions of ESI, but we argue their inclusive visions could be complemented with questions of socio-technical integration, the different interpretation of what this integration is for, and of the production of scale in ESI. Such new SSH language on ESI, we argue, is important for any researcher or policymaker interested in becoming a systems integrator or merely understanding the concept better, all over the world.

Acknowledgements We acknowledge the funding from the Scottish ClimateXChange project 'Scotland and the European Energy Union: A SocioTechnical Systems Perspective' and from the SHAPE ENERGY project, as well as the support of the Durham Energy Institute in co-organising the workshop this chapter builds upon.

\section{REFERENCES}

Bakke, G. A. (2016). The Grid. The Fraying Wires Between Americans and Our Energy Future. New York: Bloomsbury USA.

Bijker, W. E., Hughes, T. P., \& Pinch, T. (Eds.). (1987). The Social Construction of Technological Systems: New Directions in the Sociology and History of Technology. Massachusetts, CA: MIT Press.

Bolton, R., \& Foxon, T. J. (2013). Urban Infrastructure Dynamics: Market Regulation and the Shaping of District Energy in UK Cities. Environment and Planning A, 45(9), 2194-2211.

Bolton, R., Lagendijk, V., \& Silvast, A. (2018). Grand Visions and Pragmatic Integration: Exploring the Evolution of Europe's Electricity Regime. Environmental Innovation and Societal Transitions. https://doi. org/10.1016/j.eist.2018.04.001.

Edwards, P. N. (2003). Infrastructure and Modernity: Force, Time, and Social Organization in the History of Sociotechnical Systems. In T. Misa, P. Brey, \& A. Feenberg (Eds.), Modernity and Technology (pp. 185-226). Cambridge, MA: MIT Press. 
European Commission. (2015). A Framework Strategy for a Resilient Energy Union with a Forward-Looking Climate Change Policy. COM/2015/080 final.

European Commission. (2016). Clean Energy For All Europeans. COM(2016) 860 final.

European Commission. (2017). The Strategic Energy Technology (SET) Plan. Publication Prepared Jointly by European Commission's Directorates-General for Research and Innovation, Energy and the Joint Research Centre.

European Parliament and Council. (2009). Concerning Common Rules for the Internal Market in Electricity and Repealing Directive 2003/54/EC (Text with EEA relevance). Directive 2009/72/EC.

Farsi, M., Fetz, A., \& Filippini, M. (2008). Economies of Scale and Scope in Multi-utilities. The Energy Journal, 29(4), 123-143.

Goldthau, A. (2014). Rethinking the Governance of Energy Infrastructure: Scale, Decentralization and Polycentrism. Energy Research \& Social Science, 1, 134-140.

Hecht, G. (Ed.). (2011). Entangled Geographies: Empire and Technopolitics in the Global Cold War. Massachusetts, CA: MIT Press.

Hughes, T. P. (1986). The Seamless Web: Technology, Science, Etcetera, Etcetera. Social Studies of Science, 16(2), 281-292.

Jenkins, K., McCauley, D., Heffron, R., Stephan, H., \& Rehner, R. (2016). Energy Justice: A Conceptual Review. Energy Research \& Social Science, 11, 174-182.

Lagendijk, V. (2008). Electrifying Europe: The Power of Europe in the Construction of Electricity Networks. Amsterdam: Amsterdam University Press.

O'Malley, M., Kroposki, B., Hannegan, B., Madsen, H., Andersson, M., D'haeseleer, W., McGranaghan, M. F., Dent, C., Strbac, G., Baskaran, S., \& Rinker, M. (2016). Energy Systems Integration. Defining and Describing the Value Proposition (No. NREL/TP--5D00-66616). Golden, CO: National Renewable Energy Lab (NREL).

Pinch, T. J., \& Bijker, W. E. (1984). The Social Construction of Facts and Artefacts: Or How the Sociology of Science and the Sociology of Technology Might Benefit Each Other. Social Studies of Science, 14(3), 399-441.

Schot, J., \& Lagendijk, V. (2008). Technocratic Internationalism in the Interwar Years: Building Europe on Motorways and Electricity Networks. Journal of Modern European History, 6(2), 196-217.

Scottish Government. (2016). A Scottish TIMES Model: An Overview. [online]. Retrieved April 30, 2018, from http://www.gov.scot/Resource/0050/ 00508928.pdf

Shove, E., Pantzar, M., \& Watson, M. (2012). The Dynamics of Social Practice: Everyday Life and How It Changes. London: Sage. 
Silvast, A. (2017). Making Electricity Resilient: Risk and Security in a Liberalized Infrastructure. Abingdon and New York: Routledge.

Szulecki, K. (2018). Conceptualizing Energy Democracy. Environmental Politics, $27(1), 21-41$.

Szulecki, K., \& Kusznir, J. (2018). Energy Security and Energy Transition: Securitisation in the Electricity Sector. In K. Szulecki (Ed.), Energy Security in Europe: Divergent Perceptions and Policy Challenges (pp. 117-148). London: Palgrave Macmillan.

Szulecki, K., \& Westphal, K. (2014). The Cardinal Sins of European Energy Policy: Nongovernance in an Uncertain Global Landscape. Global Policy, 5(1), $38-51$.

Szulecki, K., Fischer, S., Gullberg, A. T., \& Sartor, O. (2016). Shaping the 'Energy Union': Between National Positions and Governance Innovation in EU Energy and Climate Policy. Climate Policy, 16(5), 548-567.

Treaty of the Functioning of the European Union. (2012). Consolidated Version of the Treaty on the Functioning of the European Union, art. 194, C2012/326/01. http://filj.lawreviewnetwork.com/files/2011/10/EU_Citation_ Manual_2010-2011_for_Website.pdf

Van der Vleuten, E. (2004). Infrastructures and Societal Change. A View from the Large Technical Systems Field. Technology Analysis \& Strategic Management, $16(3), 395-414$.

Winskel, M. (2018). The Pursuit of Interdisciplinary Whole Systems Energy Research: Insights from the UK Energy Research Centre. Energy Research o Social Science, 37, 74-84.

Open Access This chapter is licensed under the terms of the Creative Commons Attribution 4.0 International License (http://creativecommons.org/licenses/ by $/ 4.0 /$ ), which permits use, sharing, adaptation, distribution and reproduction in any medium or format, as long as you give appropriate credit to the original author(s) and the source, provide a link to the Creative Commons license and indicate if changes were made.

The images or other third party material in this chapter are included in the chapter's Creative Commons license, unless indicated otherwise in a credit line to the material. If material is not included in the chapter's Creative Commons license and your intended use is not permitted by statutory regulation or exceeds the permitted use, you will need to obtain permission directly from the copyright holder.

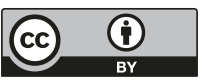

